\title{
The nature of multinucleated cells in the nasopharynx
}

\author{
M. Y. ALI \\ From the Department of Pathology, University of Singapore, General Hospital, \\ Singapore 3, Malaysia
}

SYNOPSIS Exfoliated multinucleated epithelial cells were shown to be present in nasopharyngeat smears from patients with moniliasis, tuberculous lesions, and non-specific chronic inflammations? of the nasopharynx. Multinucleated cells found in the nasopharynx were cytologically similar te the so-called measles giant cells. Because of the association of these cells with a number of chronię inflammatory lesions, their function is probably related to phagocytosis. In evidence thereof, a few multinucleated cells, presumably of epithelial origin, showed phagocytosed particles within thei莒 cytoplasm. This view is also based on corroborative evidence given by a number of workers that epithelial cells in the respiratory mucosa and in the endometrium were shown to assume phago= cytic functions comparable to those of free histiocytes.

The epithelial lining of the human nasopharynx is composed of squamous, ciliated, and transitional epithelia. On average, approximately $40 \%$ of the nasopharyngeal mucosa is covered by pseudostratified columnar ciliated epithelium (Ali, 1965). The ciliated epithelium of the nasopharynx is, morphologically, similar to that lining the trachea and bronchi but has a tendency to be taller (Papanicolaou, 1954). The most characteristic cytological features of the ciliated columnar epithelium are the cilia, the heavy cuticular border, the round to oval granular nucleus, and the perinuclear cytoplasmic vacuolation. In addition, Papanicolaou (1954) also stated that binucleation and multinucleation are not infrequent; cells of this type which have lost their ciliated border may be easily misinterpreted as malignant. Furthermore, he explained that multinucleation may be observed in malignant as well as in benign cells but, in general, its specific diagnostic significance has not as yet been determined. Ide, Suntzeff, and Cowdry (1959), however, regarded the multinucleated cells in the trachea and bronchi as atypical cells.

During the course of cytological examination of nasopharyngeal smears for cytodiagnosis of carcinoma, multinucleated cells (ciliated and non-ciliated) were frequently encountered. Numerous other structural changes in the ciliated epithelia, mainly degenerative, similar to those described by Bryan and Bryan (1953, 1959), were often found in the nasopharyngeal smears. Cytologically, the appearance of these degenerate cells was not confused with

Received for publication 5 February 1965. any of the features of malignant cells. Howevero at the beginning of this study, multinucleated cells posed some difficulty in interpretation. Although the presence of multinucleated epithelial cells in the bronchial mucosa has been recognized, there was no mention of their occurrence in the nasopharyngead mucosa. Moreover, since the function of these cells. is not well understood, a closer study of the con? ditions in which they prevail appears to be manda? tory.

The purpose of this communication is to report the frequent occurrence of multinucleated cells amongst other cells exfoliated from the huma nasopharynx and to present the conditions associ ated with their presence. The genesis and the possible function of these cells are briefly discussed.

\section{MATERIALS AND METHODS}

Nasopharyngeal swabs were taken from 138 patient suspected of having carcinoma of the nasopharynx an from 25 apparently healthy individuals. Two smears, on non-albuminised microscopic slides, were prepared fromu each swab and immediately fixed in equal parts of ether and $95 \%$ alcohol. Nasopharyngeal biopsies were the taken from the 138 patients and nasopharyngeal mucosQ from 100 necropsied medico-legal cases was utilized foo the study of the normal histology.

The cytological smears and paraffin sections of the biopsy and necropsy material were all stained wit. haematoxylin and eosin. The same stain was used for the histological and cytological preparation to facilitates comparison of various cell types in each.

The cytological preparations were examined for the presence of malignant cells and each specimen was comg 
pared with the corresponding histological slides. The smears taken from apparently normal persons were also compared with the histological appearances in the necropsy material. Binucleated and multinucleated cells, when found in the smears, were recorded on index cards bearing the relevant clinical and histological data. Thus the conditions associated with the presence of multinucleated cells were distinguished Acute inflammatory conditions were diagnosed by the presence of polymorphonuclear exudate. In chronic lesions, the presence of macrophages, plasma cells, and a predominantly lymphocytic infiltrate were essential histological features (Fig. 1a and b). In a few, increase in the mast cell population (Ali, 1964) was taken as a criterion, especially in healing lesions.

\section{RESULTS}

The smears were divided into three groups according to the corresponding histological diagnoses: those showing nasopharyngeal carcinoma (with or without mucosal ulceration), benign conditions, and normal controls (see the Table below). In the first group, there were 79 smears from histologically proven cases of nasopharyngeal carcinoma. Clinically and histologically 44 of these cases showed no ulceration of the nasopharynx. None of the smears from the 44 cases showed the presence of multinucleated cells. Each of the remaining 35 cases showed protruding and ulcerative nasopharygneal tumours. Smears from all these were positive for malignant cells but only three showed the presence of multinucleated cells. The second group, 59 smears, was representative of various inflammatory lesions, including granulomas and vasomotor rhinitis. In 17 of the 59 smears, abundant binucleate and multinucleate cells were found. The conditions associated with the prevalence of these cells were tuberculous granulomas (Fig. 1a), moniliasis, and non-specific chronic inflammation. The remainder of the smears, from 42 patients with benign lesions, showed acute suppurative conditions. Multinucleated cells were not found in any of these smears. Finally, none of the 25 control smears showed the presence of binucleate or multinucleate cells.

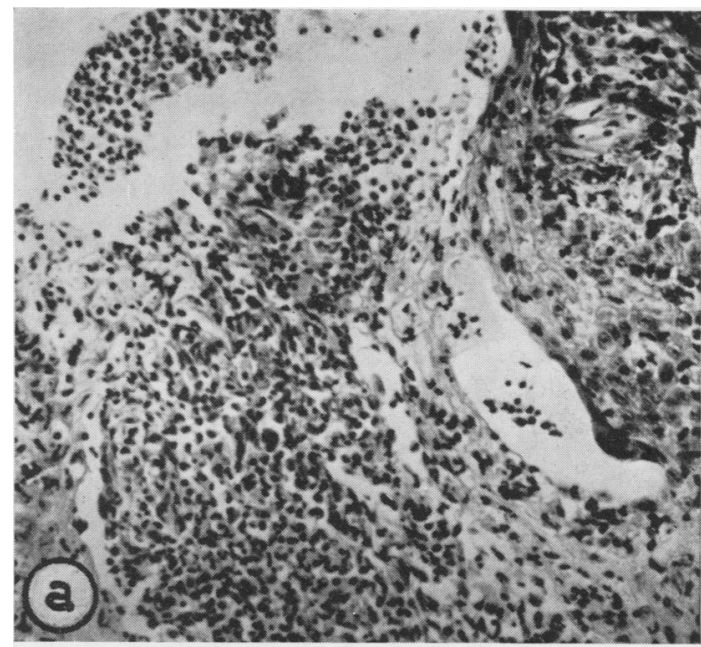

FIG. 1a. Histological section of a tuberculous lesion in the nasopharynx showing chronic inflammatory cells at its ulcer crater. Haematoxylin and eosin $\times 150$.

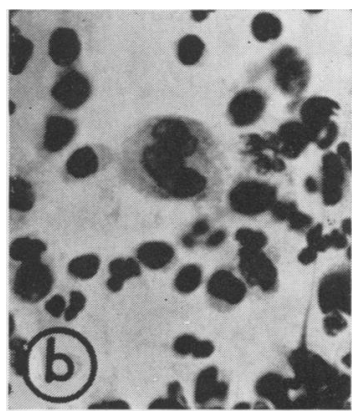

FIG. 1b. Lymphocytes and binucleate macrophage in the cytological smear from the ulcer illustrated in Fig. 1a. Haematoxylin and eosin $\times 500$.

Multinucleated epithelial cells were difficult to identify in histological sections due to crowding of the nuclei in the pseudo-stratified ciliated epithelia. However, in cytological preparations two types of multinucleated cells were found. Binucleated and multinucleated ciliated cells with up to 12 nuclei,

TABLE

OCCURRENCE OF MULTINUCLEATED EPITHELIAL CELLS IN 163 NASOPHARYNGEAL CYTOLOGICAL SMEARS Source of Material

\begin{tabular}{lccc} 
No. of Smears Examined & & \multicolumn{2}{l}{$\begin{array}{l}\text { Smears Showing } \\
\text { Multinucleated Cells }\end{array}$} \\
\cline { 1 - 1 } $\begin{array}{l}\text { Detailed } \\
\text { Record }\end{array}$ & Total & & No.
\end{tabular}

Average Frequency $(\%)$

\begin{tabular}{lccccc}
\hline Normal (controls) & & 25 & - & - & 0 \\
Carcinoma & & 79 & 3 & $3 \cdot 8$ & $3 \cdot 8$ \\
Ulcerating & 35 & & 3 & $8 \cdot 5$ & \\
Non-ulcerating & 44 & & 0 & - & \\
Infammations & & 59 & 17 & $28 \cdot 8$ & $28 \cdot 8$ \\
Chronic & 25 & & 17 & $68 \cdot 0$ & \\
Acute & 34 & & 0 & - &
\end{tabular}




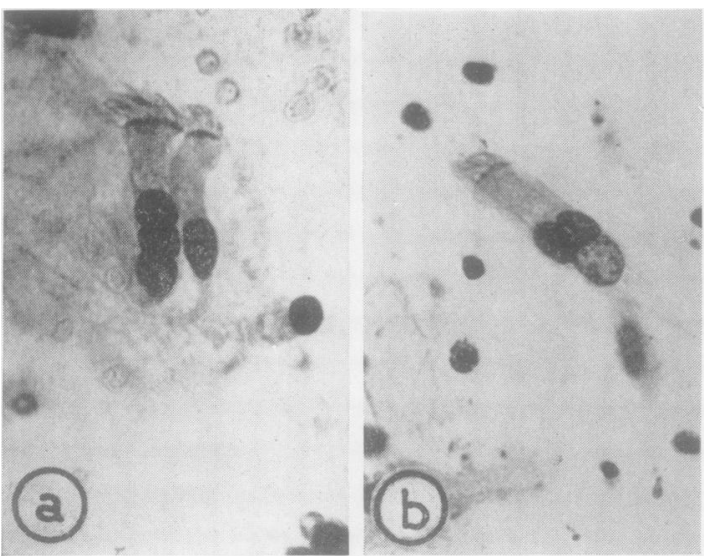

FIG. 2. Trinucleated epithelial cells (a) nuclei in a row and only slight alteration in cell width: compare with normal cell to the right; (b) triangular arrangement of nuclei and almost normal sized cell. Haematoxylin and eosin $\times 500$.

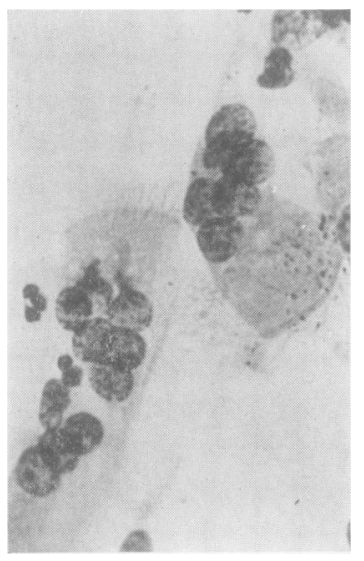

FIG. 3. Multinucleated ciliated epithelial cells. Cells about three times wider than normal and the nuclei tightly packed in the tail end. Haematoxylin and eosin $\times 500$.

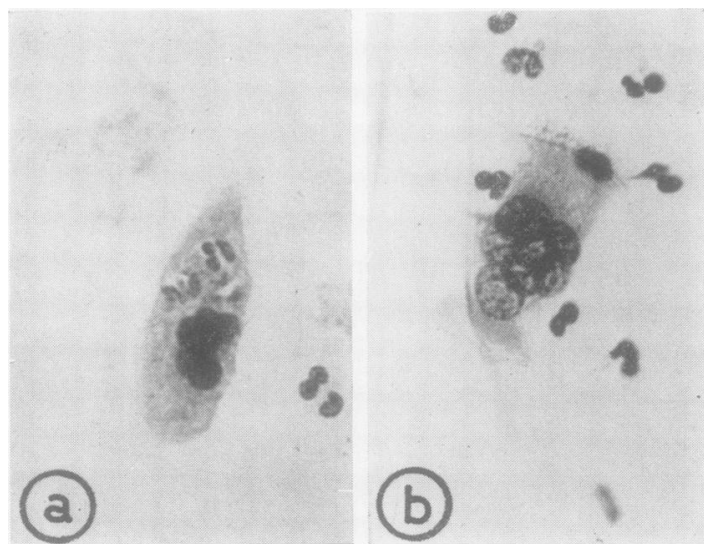

FIG. 4a. Elliptically shaped multinucleated cell containing phagocytosed particles in its cytoplasm. (b) Multinucleated giant cell showing cilia. Haematoxylin and eosin $\times 500$. the largest measuring approximately 20 microns in width, were the commonest types encountered. (Figs. 2 and 3). The other type had no identifiable cilia, was elliptical in shape, and often showeff phagocytosed particles in the cytoplasm (Fig. 4a) The shape and size of the nuclei of these cells anc their abundant cytoplasm, but for the lack of cilia showed a morphological resemblance to the multi 0 nucleated ciliated cells (Fig. 4b).

\section{DISCUSSION}

Ciliated epithelial cells are often shed as a result of infections of the respiratory mucosa. Degenerative changes in the ciliated epithelia and multinucleate $\sigma_{50}$ cells diagnostic of viral infections have been shown by Bryan and Bryan (1959). The nasopharynx, beingo a part of the upper respiratory tract, would naturally show all the structural changes that might develop as a result of irritation and infection.

The occurrence of numerous multinucleated gian $\bar{E}$ cells in the pharyngeal mucosa in the prodromal stage of measles was reported by Warthin (1931)\% However, Algana (1911) had earlier recognized these cells in the tonsils and the respiratory epithelium in necropsy specimens from cases of measles. The presence of multinucleated cells in the lymphoid tissue suggested that they were derived fromb lymphocytes or reticulum cells (Warthin, 1931) However, Semsroth (1939) reported that epithelia) multinucleated giant cells with cytoplasmic inclusion bodies were found in the respiratory mucosa in a fatal case of prodromal measles. The formation of these cells, he suggested, was by fusion of adjoining: cells which might or might not retain their cilia? Also, Masugi and Minami (1938) illustrated with clarity that the multinucleated cells in the respiratory mucosa have arisen from fusion of respiratory epithelial cells.

The measles giant cells, having acquired that name,$?$ were also demonstrated in cytological smears of nasal secretions from cases of measles by Bryan and Bryan (1959). In their description, they accepted the epithelial origin of these cells and mentioned that cilia were occasionally seen. Recently, Motteto and Szanton (1961) confirmed that the presence of the multinucleated cells in nasal secretions was diagnostic of measles. However, they realized thato these cells might occur in some chronic nasal infec $\Phi$ tions but there was little likelihood that such patients would be clinically confused with cases of measles? The finding of multinucleated epithelial cells in bronchial smears, earlier described by Papanicolaoo (1954), has recently been shown to be associated witt\$ pulmonary tuberculosis and significantly frequent iq cases of combined cancer and tuberculous disease of 
the lungs (Hoch-Ligeti and Eller, 1963). Moreover, the authors postulated that the function of the multinucleated cells, similar to that of macrophages, is related to phagocytosis.

Morphological studies alone were not altogether conclusive in establishing the mode of formation of the multinucleated epithelial cells. The epithelial origin of the so-called virus-induced multinucleated giant cells was revealed by Enders and Peebles (1954). They showed that epithelial cells in tissue cultures fused to form multinucleated cells as a direct result of invasion by measles virus. Papanicolaou and Maddi $(1958,1959)$ also produced convincing evidence to show that epithelial phagocytes were formed in tissue cultures of endometrial epithelium, particularly in the presence of cellular detritus resulting from endometrial infection or, in some instances, from contamination with Monilia. The evidence presented in favour of the view that endometrial cells assumed phagocytic function comparable to that of the free histiocytes confirmed the earlier observations of Duthie (1930) in which he found evidence of phagocytosis by the ciliated bronchial epithelium. On the other hand, cells concerned with phagocytic activities in higher vertebrates were always considered to be of mesenchymal origin (Mudd, McCutcheon, and Lucke, 1934) and the majority of workers believed that epithelial cells were non-phagocytic (Robertson, 1941).

Based on the criteria in the literature reviewed above, multinucleated epithelial cells were found in chronic and viral infections of the respiratory tract. The findings in the present study showed that the presence of multinucleated cells in smears from the nasopharynx was definitely related to chronic and granulomatous lesions. These cells, resembling the measles giant cells, were undoubtedly of epithelial origin. But it was not always possible, on a morphological basis, to differentiate between the nonciliated giant cells and other types of multinucleated macrophages. However, since epithelial cells have been shown to assume phagocytic function, there is at least presumptive evidence to show that their presence in chronic inflammatory conditions is related to phagocytosis. Giant cells of histiocytic and monocytic origins (Aronson and Elberg, 1962; Wassermann, 1963), also formed by fusion of cells, are not of the same size as the multinucleated epithelial cells. Multinucleated cells in which phagocytosed particles were identifiable had no cilia but were morphologically similar to the other ciliated giant cells in size, shape, and cytological details.

\section{REFERENCES}

Algana, G. (1911). Arch. Laryng. Rhin. (Berl.), 25, 527.

Ali, M. Y. (1964). Experientia (Basel), 20, 254.

- (1965). J. Anat. (Lond.), in the press.

Aronson, M., and Elberg, S. S. (1962). Nature (Lond.), 193, 399.

Bryan, W. T. K., and Bryan, M. P. (1953). Trans. Amer. Acad. Ophthal. Otolaryng., 57, 297. (1959). Ibid., 63, 597.

Duthie, E. S. (1930). J. Path. Bact., 33, 547.

Enders, J. F., and Peebles, T. C. (1954). Proc. Soc. exp. Biol. (N.Y.), 86, 277.

Hoch-Ligeti, C., and Eller, L. L. (1963). Acta cytol. (Philad.), 7, 258. Ide, G., Suntzeff, V., and Cowdry, E. V. (1959). Cancer (Philad.), 12, 473.

Masugi, M., and Minami, G. (1938). Beitr. Path. Anat., 101, 483.

Mottet, N. K., and Szanton, V. (1961). Arch. Path., 72, 434.

Mudd, S., McCutcheon, M., and Lucke, B. (1934). Physiol. Rev., 14, 210.

Papanicolaou, G. N. (1954). Atlas of Exfoliative Cytology. Harvard University Press, Cambridge, Mass.

- , and Maddi, F. V. (1958). Amer. J. Obstet. Gynec., 76, 601

- - , (1959). Ibid., 78, 156.

Robertson, O. H. (1941). Physiol. Rev., 21, 112.

Semsroth, K. H. (1939). Arch. Path., 28, 386.

Warthin, A. S. (1931). Ibid., 11, 864.

Wassermann, H. P. (1963). J. invest. Derm., 40, 73. 